University of Wollongong

Research Online

Faculty of Commerce - Papers (Archive)

Faculty of Business and Law

$1-11-2005$

\title{
To segment or not to segment? An investigation of segmentation strategy success under varying market conditions
}

Sara Dolnicar

University of Wollongong, s.dolnicar@uq.edu.au

R. Freitag

Federal Ministry of Social Security, Generations and Consumer Protection, Austria

Melanie J. Randle

University of Wollongong, mrandle@uow.edu.au

Follow this and additional works at: https://ro.uow.edu.au/commpapers

Part of the Business Commons, and the Social and Behavioral Sciences Commons

\section{Recommended Citation}

Dolnicar, Sara; Freitag, R.; and Randle, Melanie J.: To segment or not to segment? An investigation of segmentation strategy success under varying market conditions 2005.

https://ro.uow.edu.au/commpapers/73

Research Online is the open access institutional repository for the University of Wollongong. For further information contact the UOW Library: research-pubs@uow.edu.au 


\title{
To segment or not to segment? An investigation of segmentation strategy success under varying market conditions
}

\begin{abstract}
A computer simulation study is conducted to explore the interaction of alternative segmentation strategies and the competitiveness of the market environment, a goal that can neither be tackled by purely analytic approaches as there is neither sufficient and undistorted real market data available to deduct findings in an empirical manner. The fundamental idea of the simulation is to increase competition in the artificial marketplace and to study the influence of segmentation strategy and varying market conditions on organisational success. Success/failure is measured using two performance criteria: number of units sold and survival of organisations over 36 periods of time. Three central findings emerge: (1) the more competitive a market environment, the more successful the concentrated market segmentation strategy; (2) increased levels of marketing budgets do not favour organisations following a concentrated segmentation strategy; and (3) frequent rethinking and strategy modification impairs organisations that concentrate on target segments.
\end{abstract}

\section{Keywords}

Market segmentation, Market condition influences, Simulation

\section{Disciplines}

Business | Social and Behavioral Sciences

\section{Publication Details}

Dolnicar, S., Freitag, R. \& Randle, M. (2005). To segment or not to segment? An investigation of segmentation strategy success under varying market conditions. Australasian Marketing Journal, 13 (1), 20-35. (Australasian Marketing Journal Best Paper Award 2005) 


\title{
To Segment or Not to Segment? An Investigation of Segmentation Strategy Success Under Varying Market Conditions
}

\author{
Sara Dolnicar, Roman Freitag, Melanie Randle
}

\begin{abstract}
A computer simulation study is conducted to explore the interaction of alternative segmentation strategies and the competitiveness of the market environment, a goal that can neither be tackled by purely analytic approaches as there is neither sufficient and undistorted real market data available to deduct findings in an empirical manner. The fundamental idea of the simulation is to increase competition in the artificial marketplace and to study the influence of segmentation strategy and varying market conditions on organisational success. Success/failure is measured using two performance criteria: number of units sold and survival of organisations over 36 periods of time. Three central findings emerge: (1) the more competitive a market environment, the more successful the concentrated market segmentation strategy; (2) increased levels of marketing budgets do not favour organisations following a concentrated segmentation strategy; and (3) frequent rethinking and strategy modification impairs organisations that concentrate on target segments.
\end{abstract}

Keywords: Market segmentation, Market condition influences, Simulation

\section{Introduction}

Despite wide agreement that strategic marketing forms the basis of organisational success and the considerable amount of research that has been conducted over the past decades in areas of strategic marketing, only limited work has investigated the interrelations between market segmentation, product positioning, competition and success in the marketplace.

The aim of this study is to take one step in the direction of filling the gap by researching the interplay between market segmentation strategy and competitive market conditions, a gap that was specifically identified by Eliashberg \& Chatterjee (1985) and Kuester, Homburg \& Robertson (1999).

We choose a market simulation approach as (1) empirical data of the experimental or pseudo-experimental nature required is not available, and (2) economic and gametheoretic analyses are typically limited to very simple, highly unrealistic settings (for instance, one dimensional product attribute spaces, uniformly distributed consumer preferences, rational players). The simulation approach allows us to investigate selected strategic components under selected market conditions in a controlled experimental setting that is simplified and artificial, but realistic with respect to the main features under investigation.

This paper will firstly review prior research in the areas of market segmentation and competition, from which three research questions are derived. A computer simulation based on an artificial market environment will then be performed to test the three hypotheses and then, using the pre-determined measures of firm success, conclusions will be drawn regarding the optimal strategies for firms operating in markets with varying levels of competition. Limitations of the study and ideas for future work are also discussed.

\section{Literature Review}

Both areas central to the present study, market segmentation and competition, have been extensively investigated individually in the past.

Within the field of segmentation research three main themes can broadly be identified: (1) research aiming at improving segmentation methodology (Aldenderfer \& Blashfield, 1984; Bailey, 1994; Dolnicar \& Leisch, 2000; Dolnicar \& Leisch, 2004; Ketchen \& Shook, 1996; 
Krieger \& Green, 1996; Lilien \& Rangaswamy, 2000; Mazanec \& Strasser, 2000; Milligan \& Cooper, 1985; Milligan, 1981; Myers \& Tauber, 1977; Punj \& Stewart, 1983; Thorndike, 1953; (2) research comparatively evaluating the usefulness of different kinds of segmentation bases (Abbey, 1979; Frank, Massy \& Wind, 1972; Haley, 1968; Wedel \& Kamakura, 1998; Wind, 1978), and (3) empirically based reports on applied segmentation studies (these segmentation applications dominate in terms of quantity, a summarising report including 243 studies of this kind published in academic journals is provided by Baumann, (2000) and Dolnicar, (2003).

However, few attempts have been made in the area of market segmentation research to simultaneously account for other components of the marketing strategy, as for instance, the product positioning decision or the competitive market pressures faced. This research gap exists both (1) conceptually / methodologically as only few techniques (see below) have been suggested in the literature to analyse market data simultaneously to account for all strategic areas, and (2) empirically, as it is difficult to collect pseudo-experimental data required to investigate the effectiveness of different strategies under different market conditions. The existence of this research gap implicitly suggests that the target segment can be chosen without considering the competitive market environment and the positioning of the own and all competing brands. Two notable exceptions exist: ideal point preference mapping (Myers \& Tauber 1977, Myers 1996) and perceptions based market segmentation (Buchta, Dolnicar \& Reutterer, 2000; Mazanec \& Strasser, 2000) simultaneously explore positioning, segmentation and competition issues based on empirical data. However there is little empirical evidence for success of certain segmentation strategies under specific market conditions, evidence that would be of interest to managers who would get more than purely theoretical guidance with regard to optimal segmentation strategies in given market conditions.

The area of competition research is even more extensive and heterogeneous than segmentation research. Competition research can broadly be classified into general approaches studying the issue in an isolated manner, pure case studies and investigations of interactions between competition and other aspects of marketing.

\subsection{General Investigations into the Phenomenon of Competition}

Porter (1980) describes different forms of competition in different market settings and suggests generic strategies to choose from. Putsis \& Dhar (1998) discuss five types of competitive interaction: cooperative, non-cooperative and independent (all symmetric), leader-follower and dominant/fringe firm (asymmetric).

Models of perfect competition focus on the outcome of competition rather than the actual act of competing and suggest that perfectly competitive firms operate independently and without consideration of competitors (McAfee \& McMillan, 1996). Neoclassical economists believe perfect competition to result in the efficient allocation of resources and the maximisation of social welfare (Hunt \& Duhan, 2002). Conventional business theorists however believe that greater competition results in more effective outcomes because organisations that are able to operate more effectively and offer customers more value for money will receive more profits and flourish (Hunt \& Duhan, 2002). Hunt \& Duhan (2002) developed the interdisciplinary resource-advantage theory which allows firms to act both efficiently, as suggested by perfect competition and effectively, as proposed by conventional business wisdom.

Game theory is the dominant paradigm used in marketing to analyse the interaction between organisations operating in oligopolistic markets (Moorthy, 1985; Putsis \& Dhar, 1998; Weitz, 1985), whereby the focus is on the actual act of competing (McAfee \& McMillan, 1996). According to this view the actions of a firm are at least partly in response to the other players in the 'game', or competitors in the market, and competition is viewed as a process of decisionmaking that is done in an uncertain environment. Evolving from game theoretic models have come 'new markets' of competition which allowed decentralised decision making in situations where it had previously been done centrally and inefficiently (McAfee \& McMillan, 1996).

In the tradition of exploring competition in an aggregate manner Urban, Johnson \& Hauser (1984) suggest a quantitative criterion to determine the competitive market structure as a basis for managerial decision making, later extended by Novak \& Stangor (1987) and Kannan \& Wright (1991). Henderson (1983) lists fundamental principles for competition analysis deduced from natural sciences. 


\subsection{Case studies based on specific industries}

Wesson \& De Figueiredo (2001) explore the microbrewery market and find that aggressive entry is most successful when no budget constraints are faced and the degree of focus chosen by the new entrant significantly influences market success. Smith et al. (1991) investigate competition in the US domestic airline market focusing on firms' responses to competitor initiatives, later extended by Chen \& MacMillan (1992) who take a more fundamental and game theoretic approach to competitive response behaviour in the industry. Clearly the limitations of these studies lie in the low generalisability.

\subsection{Interactions between competition and other aspects of marketing}

Weitz (1985) noted the general lack of research into the affect of competition intensity on marketing activity. However in recent decades researchers and managers have increasingly recognised the importance of understanding the different types of competition across categories, marketing instruments and strategic groups (Putsis \& Dhar, 1998). Henderson (1983) notes: 'the success of any marketing strategy depends on the strength of the competitive analysis on which it is based' (p. 7).

Some theorists have examined the relationship between competition intensity and the overall marketing mix (Dutta \& King, 1980; Gatignon, Anderson \& Helsen, 1989; Hauser \& Shugan, 1983; Kotler, 1965; Oxenfeldt \& Moore, 1978; Robinson, 1988). Kotler (1965) presented a duopolistic dynamic competitive model which included advertising, distribution and pricing decisions, while Dutta \& King (1980) used 'metagame' analysis to develop a framework for competitive strategy development. Slade (1995) investigated the nature of competition amongst competing brands by developing a dynamic model of product rivalry in a market where organisations have a number of competitive tools including price and advertising intensity. Carpenter \& Lehmann (1985) used not only the marketing mix variables but also brand switching and product features to develop a model to investigate patterns of competition and market structure.

Although empirical research in the area of market defence strategies to respond to increasing competition is relatively thin (Kuester, Homburg \& Robertson, 1999) some researchers have begun to investigate this issue. Perhaps most significantly, Hauser \& Shugan (1983) developed the 'Defender' model which provided a framework for how firms should modify their marketing mix to respond to new entrants. The interaction between competition, positioning and segmentation was further explored by Hauser (1988) in the extended Defender model where equilibria conditions were identified and maximum differentiation was found to maximise profits. Gatignon, Robertson \& Fein (1997) investigate defence strategies for incumbents facing increased competition in the form of new entrants and recommends that the response strategy should include as few elements of the marketing mix as possible in order to avoid underspending on each element relative to its marginal utility.

\subsubsection{Competition \& Positioning}

Interaction between positioning and competition was studied by Hotelling (1929, principle of minimum differentiation) and d'Aspremont, Gabszewicz \& Thisse (1979, principle of maximum differentiation) focusing on the case of unidimensional product feature space including price in a duopoly market setting. Vandenbosch \& Weinberg (1995) extended the one dimensional Hotelling model to two dimensions, still assuming uniform distribution of consumer preferences and looking at the duopoly situation exclusively resulting in an equilibrium positioning where one attribute is at its maximum level and the second one at the minimum level for one firm and exactly the opposite for the competitor. Carpenter (1989) investigated the same interaction emphasising organisation's expenditures for advertising and distribution, finding that positioning and optimal marketing mix in terms of these expenditures are highly dependent. Stearns et al. (1995) studied the effect of different positioning approaches under varying competitive market situations using empirical data of new entrants and found significant interaction with inconsistent findings for different settings.

\subsubsection{Competition \& Price}

Rao \& Shakun (1972) developed a static pricing model with price as the only decision variable. Others such as Thompson \& Teng (1984) later proposed dynamic models which consider price as a control variable in deriving equilibrium strategies. A study by Rao \& Bass (1985) explored how competition influences dynamic pricing of new products by focusing on the development of industry pricing in different competitive settings. They modelled competition as a dynamic Nash equilibrium and extended analysis of dynamic pricing to an undifferentiated oligopoly by addressing the problem analytically, numerically and empirically. 
Ansari, Economides \& Ghosh (1994) explored the interaction of positioning and price in a competitive environment in a game theoretic manner. They relaxed the assumption of uniformly distributed consumer preferences illustrating the difference in results if this assumption is made. The investigation included competitive situations with different numbers of competing firms and found that differentiation reduces price competition and increases profits, optimal positions depend on the number of organisations and the level of consumer heterogeneity. McAfee \& McMillan (1996) also discuss the value of the game-theoretic approach to marketers and the affect of competition on product positioning and pricing. They emphasise the value of creating competition for a new product as an effective way of ensuring low prices in the longer term.

Ramaswamy, Gatignon \& Reibstein (1994) focus on price and selling and investigate cooperative and retaliatory competitive strategies, discussing the extent to which different levels of competition influence marketing behaviour. Clarke \& Dolan (1984) simulate a range of pricing strategies in a sequential entry context where the entry date is known, while Spence (1981) also considers sequential entry in developing a dynamic model of competition focusing on the issue of declining costs.

\subsubsection{Competition \& Product}

Ballou \& Pipkin (1980) developed a framework for modelling competition and investigated product positioning strategies in oligopolistic markets that are highly competitive and uncompetitive. Interaction between product quality and competition was also studied by Moorthy (1988) in one dimensional product attribute space, while McGuire \& Staelin (1983) focused on competition and product substitutability using a linear duopoly model and established equilibrium conditions for different channel structures. Lane (1980) investigated the relationship between product positioning and pricing and levels of competition in oligopolistic markets with sequential entry.

\subsubsection{Competition \& Advertising Expenditure}

Friedman (1958) used game theory as a basis for a static model of advertising expenditure using different scenarios, which was later developed by Shakun who introduced interdependencies between segments, and Gupta \& Krishnan (1967) who included multiple competitors and additional controllable variables.
Schmalensee (1978) proposed a dynamic model of advertising expenditure in which he recognised the ongoing nature of advertising decision making. This was later extended to include finite planning horizons and the investigation of duopolistic situations for growing and non-growing markets (Deal, 1979; Erickson, 1985; Wang \& Wu, 2001), and oligopolistic situations with pricing included as an additional control variable (Thompson \& Teng, 1984).

\subsubsection{Competition \& Market Segmentation}

The interplay between organisational market segmentation strategy and different competitive market situations has so far received little attention (Eliashberg \& Chatterjee, 1985), although recommendations for managerial decision making on a strategic level cannot be made in an isolated manner.

Lilien \& Rangaswamy (2000) introduce the STP approach, a stepwise procedure integrating segmentation target choice and positioning in a sequential manner. Mazanec \& Strasser (2000) and Buchta, Dolnicar \& Reutterer (2000) propose and illustrate an integrated approach of analysis including segmentation, positioning and competition based on empirical three way data (PBMS, perceptions based market segmentation). Wesson \& De Figueiredo relate the issues of competition and market segmentation to each other in a case study, empirically finding that new entrants into the microbrewery industry are better off serving small market segments.

\section{Research Questions}

The central issue to be investigated in this study is the interaction between different segmentation strategies and the level of competition within the market in which a firm is operating. As opposed to most previous studies on this interaction, we do not investigate the effects of market entry (Gatignon, Robertson \& Fein, 1997; Hauser \& Shugan, 1983; Lane, 1980; Spence, 1981; Stearns et al., 1995; Wesson \& De Figueiredo, 2001). Three hypotheses are to be tested in this study.

Firstly, it has been widely postulated that higher levels of competition favour a concentrated market segmentation strategy, and although this assumption is not surprising, there is so far little evidence for this assertion. Prior work investigating the relationship between competition and market segmentation strategy have either used economic approaches making limiting assumptions or of empirical 
approaches and have consequently been limited in their generalisability. For example Hauser's study (1988) demonstrates higher price equilibria for differentiated product positions. Ansari, Economides \& Ghosh (1994) found that greater heterogeneity in consumer preferences results in maximum segmentation and differentiation, increased market share, and less price competition resulting in higher profits. These investigations, however, are limited to 2-4 competitors. Wesson \& De Figueiredo (2001), in their empirical study, found an association of segmentation and success of new entrants. Stearns et al. (1995) found that new firm survival could not be predicted by examining an industry in isolation, but that when the location and strategy of the firm were also considered survival chances could be predicted. For example, service industry firms operating in metropolitan locations were far more likely to succeed if they pursued a narrow or niche marketing strategy. Therefore the first hypothesis to be tested is:

\section{Hypothesis 1: Higher levels of competition favour a concentrated market segmentation strategy.}

The second hypothesis relates to advertising expenditure levels. Friedman (1958) studied the interaction of competitive strategy and advertising expenditure finding that the optimal advertising expenditure differs for each firm and is proportional to both the potential sales in the area and the share of total advertising in the area; and that when a firm has less advertising funding available than a competitor it should adopt a mixed strategy, increasing the probability of reaching any given customer. Shakun's study (1965) indicates that the level of advertising expenditure spent selling the product of one firm proportionately influences sales of the corresponding product of the other firm, limiting the investigation to two competitors only. Gupta \& Krishnan (1967) assume multiple competitors but limit the controllable variables of the firm to price and promotion, identifying conditions under which competitors with differing levels of resources should use price and promotions as their major competitive tool, depending on their respective resource levels. The knowledge gap however lies in the investigation of high levels of advertising expenditure and the most appropriate segmentation strategy for firms finding themselves in this position. Therefore, we will be testing the following assumption.

Hypothesis 2: Higher advertising expenditure levels favour the concentrated market segmentation strategy more than the mass marketing strategy.
To the authors' knowledge, no prior investigations of frequency of marketing and segmentation strategy revision on market performance have been undertaken. It has been generally postulated, however, that the periodic reassessment of marketing strategy is a crucial organisational success factor (Kotler, 1999, 2003; McDonald, 2002; McDonald \& Payne, 1996; Schnaars, 1998). This is because the customisation to the target group chosen can be optimised steadily. This is reflected in hypothesis three:

Hypothesis 3: Frequent revision of strategy favours the concentrated market segmentation strategy.

\section{The Simulation Environment: an Artificial Consumer Market}

A market simulation approach has been chosen for this study primarily due to the unavailability of the experimental empirical data required. Using a simulation approach, selected strategic components can be investigated under specific market conditions in a controlled setting.

The computer simulation is based on an artificial consumer market environment (SIMSEG/ACM by Buchta \& Mazanec, 2001; Buchta et al., 2004) that is outlined in Figure 3. The main purpose of this environment is to provide a market-like framework, which supports, ceteris paribus experiments in order to gain insight on how successful certain corporate strategies are in a competitive marketplace. The central research question is formalised within this environment by constructing artificial actors (agents) that compete with each other. In the present study, these actors represent organisations. They are designed to make use of different decision rules concerning their market segmentation strategy. The organisations are confronted with each other and each other's market strategies in a marketplace. Over the multiple replications of the simulation the market conditions are systematically varied. By simulating a long period of time (three years), insights are gained about the success of particular strategies under given circumstances. These conditions are defined a priori. In this experiment the following components define the artificial marketplace:

Product: The product consists of 12 attributes that can be perceived by a customer. These could be associations that tourists have with destinations (cool, trendy, relaxing, safe, expensive, etc.) or perceived characteristics of a car (fast, sexy, fancy, luxurious, etc.). These 12 attributes are designed to load on four hidden 
dimensions (factors), three attributes per dimension. For instance, the attributes cool and trendy for tourist destinations are likely to load on a different underlying factor than safety. All dimensions represent information that is purely influenced by advertising action, as the production is not of fundamental importance for the question under investigation and was therefore not modelled in the simulation.

Customers: The world consists of many consumers who have heterogeneous preferences with regard to the 12 product attributes. Six such market segments are modelled, the preferences of which are given in Table 1 .

Every column represents one hidden dimension (factor), every row represents one segment. For instance, Factor 1 could represent safety related tourist destination

Table 1: Consumer preference segments

\begin{tabular}{|l|c|c|c|c|}
\hline & Factor 1 & Factor 2 & Factor 3 & Factor 4 \\
\hline Segment 1 & $\mathrm{I}$ & $\mathrm{I}$ & $\mathrm{R}$ & $\mathrm{R}$ \\
Segment 2 & $\mathrm{R}$ & $\mathrm{R}$ & $\mathrm{I}$ & $\mathrm{I}$ \\
Segment 3 & $\mathrm{R}$ & $\mathrm{I}$ & $\mathrm{R}$ & $\mathrm{I}$ \\
Segment 4 & $\mathrm{R}$ & $\mathrm{R}$ & $\mathrm{R}$ & $\mathrm{R}$ \\
Segment 5 & $\mathrm{I}$ & $\mathrm{I}$ & $\mathrm{I}$ & $\mathrm{I}$ \\
Segment 6 & $\mathrm{I}$ & $\mathrm{R}$ & $\mathrm{I}$ & $\mathrm{R}$ \\
\hline
\end{tabular}

Note: $I=$ irrelevant; $R=$ relevant

perceptions and include three attributes (safety, familiarity and low crime rate) and Segment 1 could be the segment of young tourists travelling with friends and mainly interested in an exiting and adventurous holiday. Furthermore, Table 1 specifies whether the Factors are relevant or irrelevant to the segments in the marketplace: an 'I' indicates that the attributes forming this Factor are irrelevant to a segment, whereas an ' $\mathrm{R}$ ' stand for relevant. Thus, Segment 1 does not care about the first three items (which could mean that young adventure-seeking tourists are not evaluating a tourist destination on the basis of the safety), whereas the information about the last three items is studied very carefully by this group of customers when they make a buying decision. The preferences of the segments remain fixed during the entire simulation. Segment sizes are unequal (with segment 3 including 50 percent of the customers and every other segment 10 percent). Each customer buys exactly one product in each period (non-purchase is not an option).
Competitors: Two kinds of organisations compete in the artificial marketplace where organisational behaviour is assumed to be bounded rational. The two organisational prototypes are therefore developed to follow very simple decision rules.

Mass marketer: They do not construct consumer market segments. All potential buyers are addressed with the same advertising message. The mass marketer creates this message by accentuating product attributes that are strongly perceived among buyers of the mass marketer's product in the past period. The mass marketer thus assumes a continuing causal relation between attribute perception and a buying act in the following period. The functioning of this organisation (the bounded rational behaviour rule) is outlined in Figure 1.

Segmenter: They create a partition of the consumers' based on their perception of the own brand. For advertising message development, the segmenter first chooses the group of individuals with the highest number of buying acts in the past period and then affirms attributes which are perceived by more than $50 \%$. This message is targeted at all buyers of the own brand. An outline is provided in Figure 2.

Simulation cycle: One simulation period starts with organisational decisions that are fed into the artificial consumer market. These decisions include the development of the advertising message and the selection of the market segment to be targeted (in case of the segmenter). After all computations within the artificial world are executed (customers match their preferences with the perceptions of the products in the marketplace as influenced by advertising action), the actors receive a summary of market performance including consumer choices (who bought which product), and the beliefs or perceptions of the customers on all 12 product attributes. A summary of the computations that take place in the SIMSEG simulation environment is provided in Figure 4.

\section{Measures of Organisational Performance}

The typical performance measures used in segmentation studies are profit, sales and market share. In competition analysis survival dominates the list of criteria explored. In this article the effect of the strategy-competitioninteraction is investigated for two different performance measures representing different organisational goals encountered: the number of units sold is the general success measure (representing profit and revenues as 
Figure 1: Organisational behaviour under the mass marketing strategy

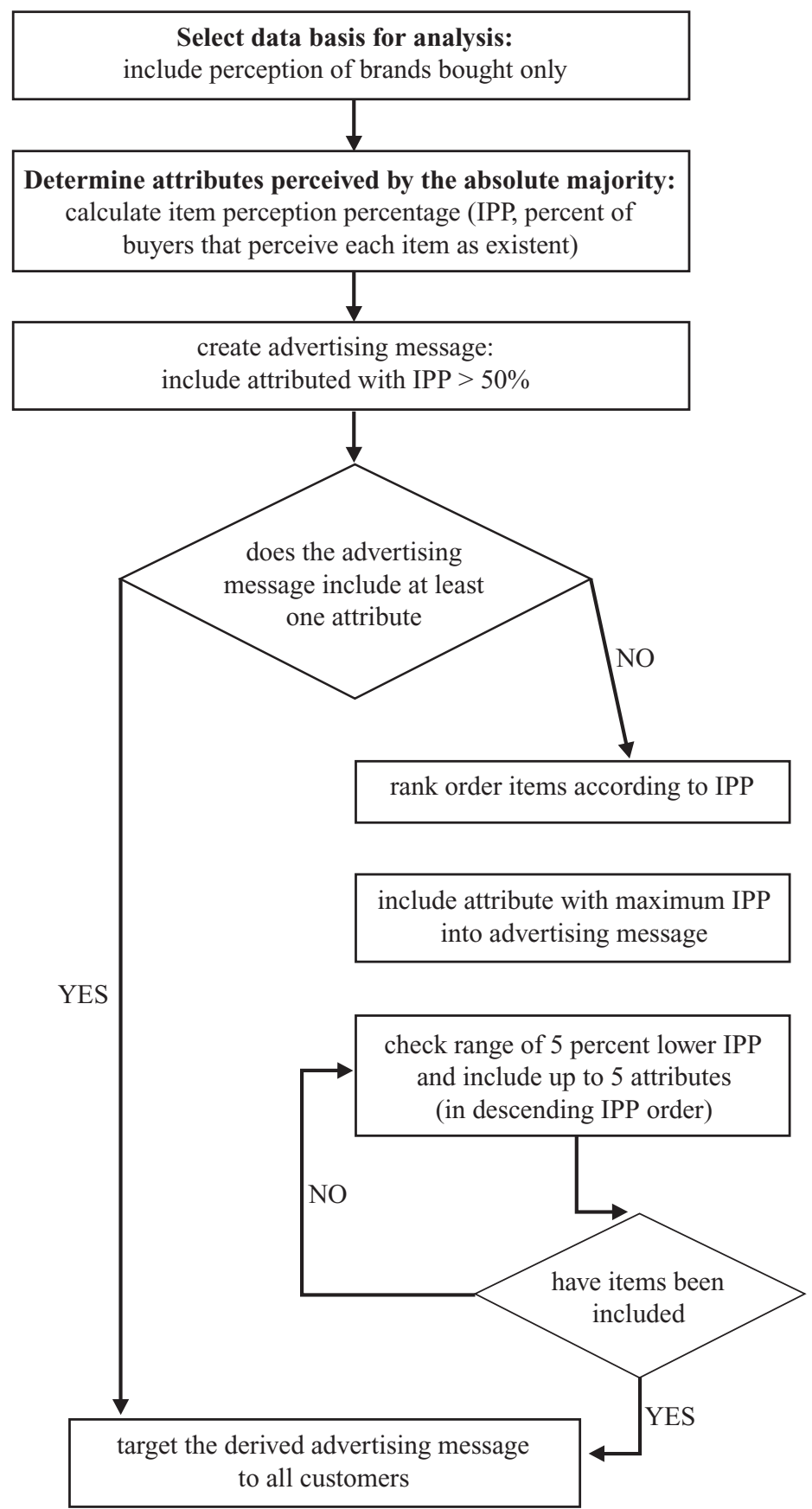

well in this particular simulation because the price module was excluded) and survival representing the long-term perspective of the organisation.

Number of units sold: The simplest way to measure success or undertake success comparisons is to take a look at the total units sold. As price is set fixed in our simulation this would be the equivalent to a sales criterion as well as a market share indicator.

Survival: Another common way to evaluate corporate success in a competitive environment is to monitor 
Figure 2: Organisational behaviour under the segmenter strategy

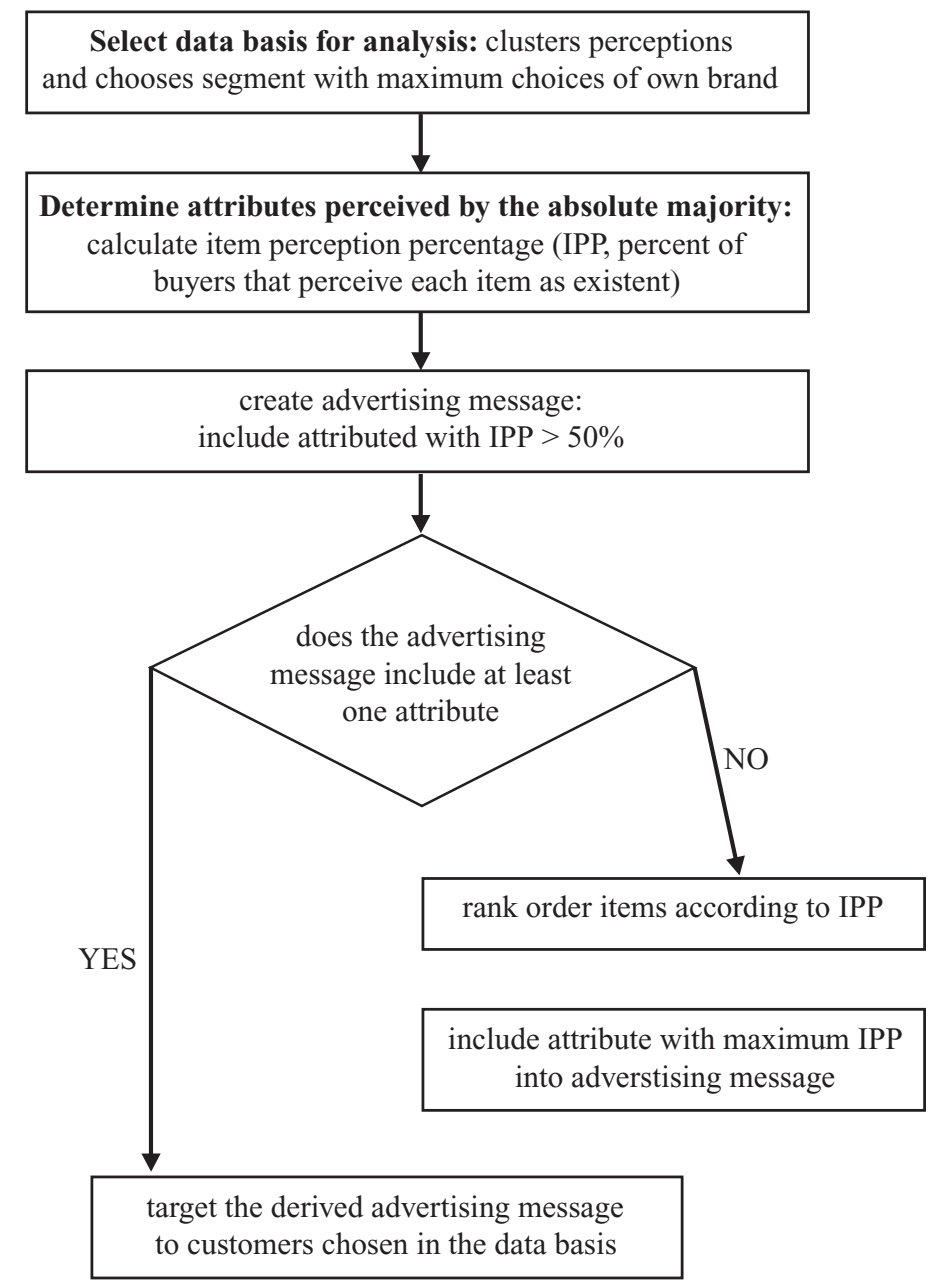

which companies survive in the long run (Stearns et al., 1995), an approach very typical for new venture success investigations. This criterion can be measured in a binary manner, allowing the conclusion that surviving companies acted more successfully in the marketplace in the long run than non surviving companies.

\section{Experimental Design}

Every simulation has a duration of 36 periods with one period representing one month. The number of independent simulations is a result of the full factorial experimental design based on the following factors and factor levels:

- Advertising budget: low (100) and high (200 monetary units)
- Thinking cycle (this is the frequency of the possibility to revise the strategy): every simulation period and every 6 th simulation period

- number of organisation in the marketplace: 2, 3, 5, 7 and 10

Each simulation was repeated ten times. The experimental design is outlined in Figure 4, providing the exact mix of mass marketers and segmenters competing in the marketplace in each scenario.

\section{Results}

Results based on the number of units sold as the performance measure: Analyses of variance are computed assuming a linear model where units sold function as the dependent variable and the amount of 
Figure 3: Outline of basic SIMSEG/ACM functioning

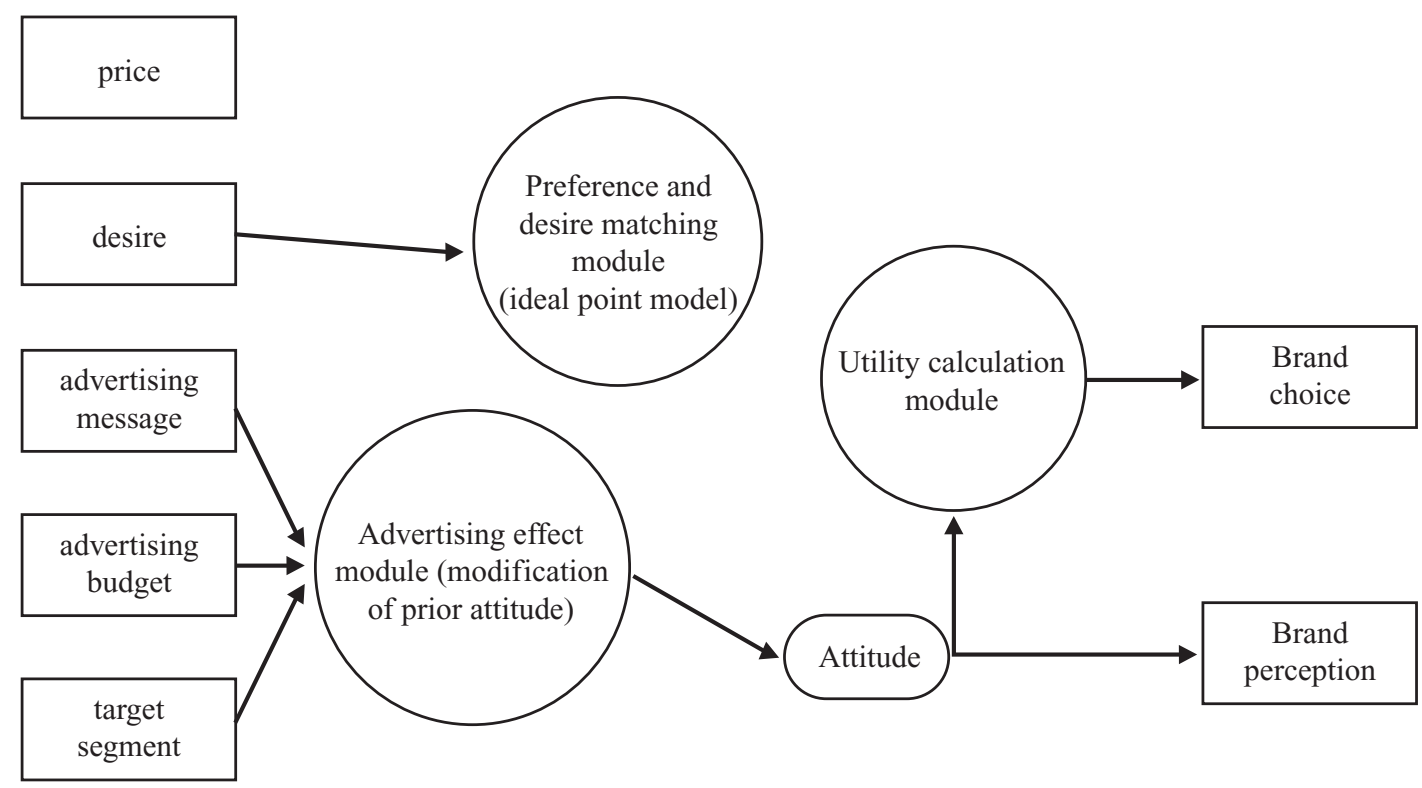

advertising budget and the length of the thinking cycle represent the independent variables. First order interactions are included. Separate analyses are computed for each competitive setting (consisting of ten replications under identical conditions).

Figure 5 illustrates these results visualised by means of box plots where the top two quadrants show results under the condition of high marketing budgets and the bottom quadrants for low marketing budgets. The right hand side of the plot provides results under the condition that strategic reorientation of the organisation was possible in every sixth period, whereas the left hand side allowed strategy changes in each period.

The major finding that results from the simulations conducted, is that organisations that choose to segment the consumers and focus on target markets are more successful in highly competitive environments; when two organisations compete (adjusted $\mathrm{R}$ squared .88, $p$ value $<.001)$, the segmenter is significantly less successful than the mass marketer. In addition, longer thinking cycles (every sixth period of time) significantly favour the performance of the segmenters in highly competitive environments. The latter effect is caused by the fact that the segmenter tends to switch market niches and the advertising profile when the choice of possible sub markets is large due to low competition.
In the case of three competing firms (adjusted $\mathrm{R}$ squared $.48, p$-value $<.001$ ) the segmenter performs significantly worse then the mass marketers, with high budget additionally decreasing performance level of the segmenter because mass marketers can more efficiently advertise to their large number of customers, whereas segmenters targeting smaller groups of potential buyers reach saturation levels. The linear model including five competitors in general does not fit very well (adjusted $\mathrm{R}$ squared .19, $p$-value $<.001)$. Significance values indicate that the segmenters' performance is inferior, longer thinking cycles favours them while impairing success of mass marketers. The same is true for the seven-competitors scenario (adjusted $\mathrm{R}$ squared .25 , $p$ value $<.001)$, supporting the finding that long thinking cycles are in favour of the segmenter strategy. In the market with ten competitors (Figure 5) all segmenters turn out to be significantly more successful. Marketing budget plays an important role, with higher budgets impairing the success of segmenters and long thinking cycles benefiting them.

\section{Results based on the survival performance measure:} Survival was investigated in the last simulation period. Firms that did not sell any products at all (market share equals zero) failed to survive in this marketplace. The results are given in Table 2 where the descriptions of the scenarios are given in columns 1 and 2 . The three right- 
Figure 4: Experimental Factors and Factor Levels

\begin{tabular}{|c|c|c|}
\hline $\begin{array}{c}\text { marketing } \\
\text { budget } \\
(2 \text { levels })\end{array}$ & $\begin{array}{l}\text { thinking cycle } \\
\text { (2 levels) }\end{array}$ & $\begin{array}{l}\text { number of } \\
\text { agents } \\
\text { (5 levels) }\end{array}$ \\
\hline $\begin{array}{c}100 \text { monetary } \\
\text { units }\end{array}$ & $\begin{array}{l}\text { every period } \\
\text { of time }\end{array}$ & $\begin{array}{l}1 \text { mass marketer } \\
1 \text { segmenter }\end{array}$ \\
\hline \multirow[t]{4}{*}{$\begin{array}{c}200 \text { monetary } \\
\text { units }\end{array}$} & $\begin{array}{c}\text { every sixth period } \\
\text { of time }\end{array}$ & $\begin{array}{l}2 \text { mass marketer } \\
1 \text { segmenter }\end{array}$ \\
\hline & & $\begin{array}{l}3 \text { mass marketer } \\
2 \text { segmenter }\end{array}$ \\
\hline & & $\begin{array}{l}5 \text { mass marketer } \\
2 \text { segmenter }\end{array}$ \\
\hline & & $\begin{array}{l}7 \text { mass marketer } \\
3 \text { segmenter }\end{array}$ \\
\hline
\end{tabular}

hand columns provide the number of organisations that did not survive the simulated three-year period of time. Each of the three columns specifies the number of competitors these organisations faced. For instance, if the strategy could be revised each period (thinking cycle 1) and the advertising budget was low (100), 1 organisation died in a highly competitive market and this was a mass marketer.

It becomes apparent from this table that all firms survive in the marketplaces with low competition. Both in the two- and three-competitor-marketplaces all firms operate and sell their products until the last period of time simulated. In all simulation runs except for the fivecompetitor-scenario, exclusively mass marketers fail to survive. As can be seen, more mass marketers are unable to cope with competition in general (and especially under the conditions of low advertising budget and long periods of time without adaptation of the advertising message and the segment targeted). The reasons are twofold: First, the mass marketer in general suffers more from low budgets than the segmenter does (larger amount of potential buyers the advertising message is addressed to). Second, mass marketers suffer from the fact that segmenters perform better when strategic thinking cycles are longer because the rule of the segmenter supports rapid change that on the long run does not optimally influence the advertising effectiveness and thus the customer perceptions. Exactly the opposite reasoning explains the one death of a segmenter in the five-competitors market environment with high advertising budget and frequent possibility to change the advertising message.

In sum, three findings can be deduced from investigating this performance measure: (1) under the market conditions modelled, non-survival is a rare event in general, (2) the segmenters beat the mass marketers with respect to the survival criterion and (3) the more competitors offer their products in the marketplace, the higher the probability of firms not surviving the entire simulation period.

With regard to the proposed research questions, the simulation results lead to following conclusions:

Hypothesis 1: The concentrated segmentation strategy is found to be more successful under the condition of high competition with regard to organisational performance.

Hypothesis 2: Increased advertising expenditure is not found to favour the concentrated segmentation 
Figure 5: Box Plot of Simulation Results with 10 Competitors

(mass marketers coded as "1", "2", “3", “4”, " 5 ", “6” and "7", segmenters as "8", "9" and "10")

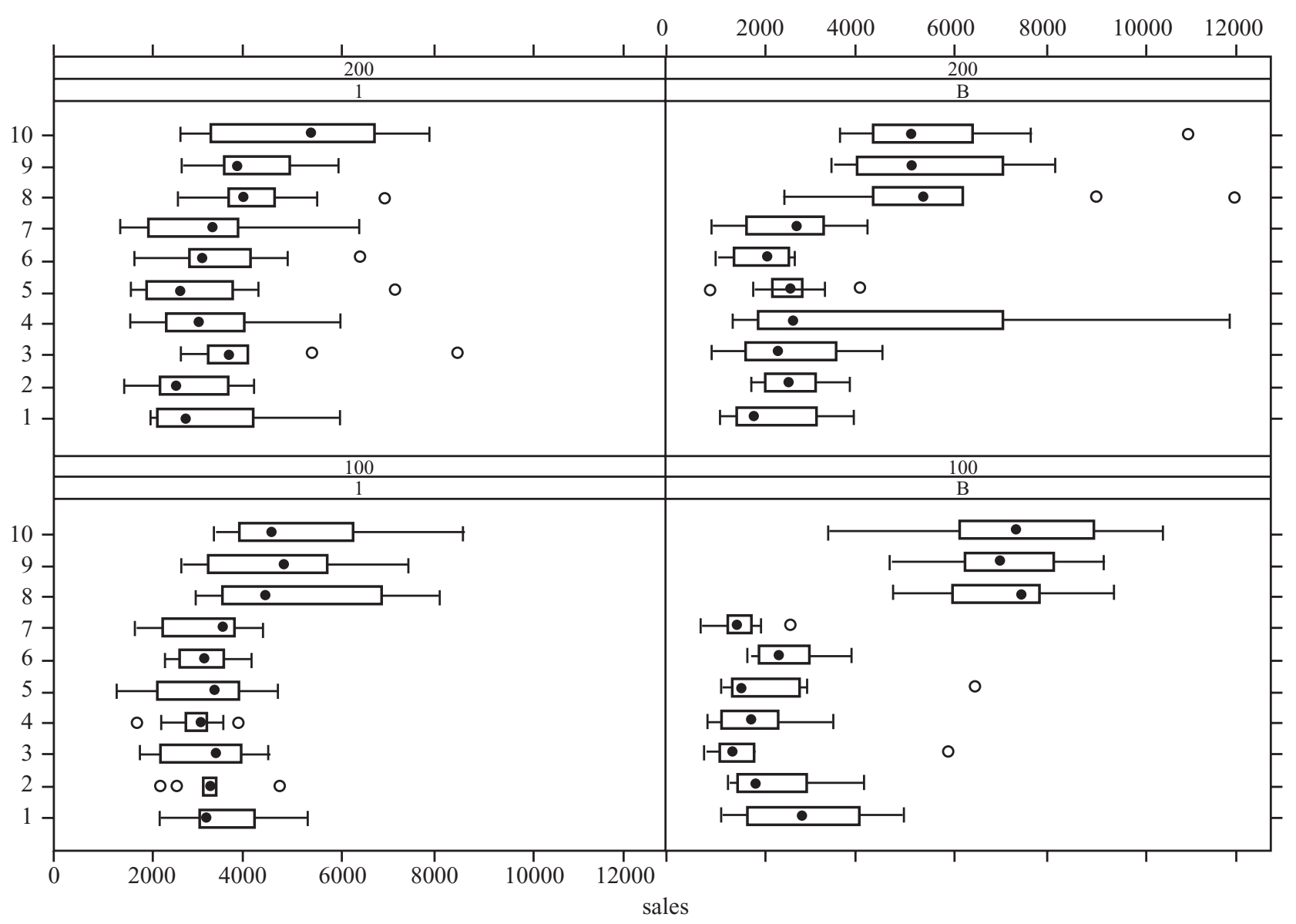

strategy. On the contrary, higher marketing budget levels for all competitors turn out to significantly impair the success of segmenters in the case of number of units sold used as performance measure. The same is true where the survival criterion is used instead of the performance measure, although the contrary effect is not detected.

Hypothesis 3: The opportunity to review the strategy more frequently does not lead to increased market success of the segmenter. On the contrary, segmenters are found to suffer from the multitude of possible segments when competition is low, for both performance measures.

In sum, the concentrated segmentation strategy seems to provide an advantage in a market with high competitive pressure. Log-file analysis of consecutive periods allows insight into the market developments in every single simulated month over the entire period of the simulation. The fundamental functioning as extracted is as follows: Mass marketers advertise the same product attributes, the attributes perceived most often to apply among the buyers of the total market. Additional competitors that act in accordance with the mass marketing rule thus reduce the market size for this strategy. More competition among mass marketers only therefore decreases the number of units sold for all organisations targeting the entire market. Segmenters that attack mass marketers by choosing to advertise product attributes identical or very similar to those promoted by the mass marketers have stronger advertising effectiveness due to a smaller group of individuals exposed to the advertising message. Segmenters that target a niche market and therefore advertise a product profile that is very distinct in the marketplace take advantage of the fact that there is no or very low competition for the product offered. As 
Table 2: Non-survival Results

\begin{tabular}{|l|c|c|c|c|}
\hline Thinking cycle & Advertising budget & $\begin{array}{c}\text { Scenario } \\
\text { with competitors }\end{array}$ & $\begin{array}{c}\text { Scenario } \\
\text { with 7 competitors }\end{array}$ & $\begin{array}{c}\text { Scenario } \\
\text { with 5 competitors }\end{array}$ \\
\hline each period (1) & low (100) & 1 (mass marketer) & 1 (mass marketer) & 0 \\
each period (1) & high (200) & 0 & 0 & 1 (segmenter) \\
every sixth period (6) & low (100) & 4 (mass marketers) & 1 (mass marketer) & 0 \\
every sixth period (6) & high (200) & 2 (mass marketers) & 0 & 0 \\
\hline
\end{tabular}

long as competition is low, mass marketers beat segmenters because they influence a large number of consumer opinions in the favoured product perception dimensions, whereas the segmenter only influences a small number, thus generating less buying acts. With increasing competition the pure size effect vanishes and the segmenter strategy is more successful due to either increased advertising effects or niche targeting.

\section{Conclusions, Limitations and Future Work}

A computer simulation study was conducted investigating the interaction of alternative segmentation strategies and the competitiveness of the market environment. The artificial world that was developed to represent the aspect of market reality relevant to our research questions is a mature market (with no new entries), containing preference segments with fixed preferences over the entire three simulated years. Each consumer buys exactly one product a year, advertising effects are cumulative, but past organisations' strategy mistakes cannot not be fed back into future strategy. Two kinds of organisations compete in the market place: mass marketers and segmenters. Both follow a simple segment selection and advertising message development rule and can occur multiple times in the market.

The following central conclusions can be drawn from the simulation: (1) the more competitive a market environment, the more successful the concentrated market segmentation strategy; (2) increased levels of marketing budget for all competitors does not favour segmenters, as they reach advertising effect saturation levels earlier; (3) frequently rethinking and modifying the strategy is not recommended for organisations following a concentrated segmentation strategy because cumulative advertising effects over multiple periods of time are not taken advantage of if the target segment is modified too often.

These findings were based on the analysis of two different performance measures: the number of units sold and organisation survival. The latter was found not to be very informative for this particular experiment, as the number of organisations not surviving the simulations was rather low. The number of units sold served well as performance measure for the simulation set up.

Within the constraints of simulation experiments, our study is limited by the following restrictions that were deliberately excluded from investigation but interesting for future simulations with different research questions: (1) price was set equal for all organisations; (2) no agent memory was modelled (learning from failures in the past therefore is not possible); (3) consumers in the artificial world modelled have fixed preferences and therefore do not change aspiration levels in reaction to market development and finally; (4) advertising budget levels were able to be increased for all competing organisations where, for instance, niche marketers may realistically have less resources to do this.

\section{Acknowledgements}

This research project was supported by the Austrian Science Foundation (FWF) under Grant SFB 010 (Adaptive Information Systems and Modelling in Economics and Management Science') and conducted 
during Sara Dolnicar's appointment at the Institute for Tourism and Leisure Studies at the Vienna University of Economics and Business Administration. We wish to thank Christian Buchta and Josef Mazanec for making the SIMSEG/ACM environment available for simulation experiments and supporting us in troubleshooting.

\section{References}

Abbey, J.R., 1979. Does life-style profiling work? Journal of Travel Research 18, 8-14.

Aldenderfer, M.S., and Blashfield, R.K., 1984. Cluster Analysis, Sage Series on Quantitative Applications in the Social Sciences, Sage Publications, Beverly Hills.

Ansari, A., Economides, N., and Ghosh, A. 1994. Competitive positioning in markets with nonuniform preferences. Marketing Science 13, 248-273.

Bailey, K.D., 1994. Typologies and Taxonomies: An Introduction to Classification Techniques, Sage University Paper Series on Quantitative Applications in the Social Sciences, Sage, Thousand Oaks.

Ballou, D.P., Pipkin, J.S., 1980. Competitive strategies: A cognitive choice model. Omega 8 (1), 53-62.

Baumann, R., 2000. Marktsegmentierung in den Sozialund Wirtschaftswissenschaften: eine Metaanalyse der Zielsetzungen und Zugänge, Diploma thesis at Vienna University of Economics and Management Science, Vienna.

Buchta, C., Dolni_ar, S., and Reutterer, T., 2000. A Nonparametric Approach to Perceptions-Based Market Segmentation: Applications, Series: Interdisciplinary Studies in Economics and Management Volume II, Springer, Berlin.

Buchta, C., and Mazanec, J., 2001. SIMSEG/ACM - a simulation environment for artificial consumer markets. Working Paper Series of the SFB "Adaptive Information Systems and Modelling in Economics and Management Science", No. 79.

Buchta, C., Mazanec, J.A., Schuster, U., Wock1, J., 2004. Building Artificial Consumer Markets. In: Taudes, A. (Ed.), Adaptive Systems and Modelling in Economics and Management Science, Springer, Vienna-New York.

Carpenter, G.S., and Lehmann, D.R., 1985. A Model of Marketing Mix, Brand Switching, and Competition. Journal of Marketing Research 22 (3), 318-329.

Carpenter, G.S., 1989. Perceptual position and competitive brand strategy in a two-dimensional twobrand market. Management Science 35, 1029-1044.

Chen, M.J., and MacMillan, I.C., 1992. Nonresponse and delayed response to competitive moves: The roles of competitor dependence and action irreversibility. Academy of Management Journal 35 (3), 539-571.

Clarke, D.G., Dolan, R.J., 1984. A simulation analysis of alternative pricing strategies for dynamic environments. Journal of Business 57(1), 179-200.

D’Aspremont, C., Gabszewicz, J., and Thisse, J., 1979. On Hotelling's stability in competition. Econometrica 47, 1145-1150.

Deal, K.R., 1979. Optimizing advertising expenditures in a dynamic duopoly. Operations Research 27 (4), 682692.

Dolni_ar, S., and Leisch, F., 2004. Segmenting markets by bagged clustering. Australasian Marketing Journal 12 (1), 51-65.

Dolni_ar, S., 2003. Using cluster analysis for market segmentation - typical misconceptions, Established methodological weaknesses and some recommendations for improvement. Australasian Journal of Market Research 11 (2), 5-12.

Dolni_ar, S., Leisch, F., 2000. Behavioral market segmentation using the bagged clustering approach based on binary guest survey data: Exploring and visualizing unobserved heterogeneity. Tourism Analysis 5 (2-4), 163-170.

Dutta, B.K., and King, W.R., 1980. A competitive scenario modelling system. Management Science 26 (3), 261-273.

Eliashberg, J., Chatterjee, R., 1985. Analytical models of competition with implications for marketing: Issues, findings and outlook. Journal of Marketing Research 22 (3), 237-261.

Erickson, G.M., 1985. A model of advertising competition. Journal of Marketing Research 22, 297304.

Frank, R.E., Massy, W.F., and Wind, Y., 1972. Market Segmentation, Prentice-Hall, Engelwood Cliff.

Friedman, L., 1958. Game-theory models in the allocation of advertising expenditures. Operations Research 6 (5), 699-709.

Gatignon, H., Anderson, E., and Helsen, K., 1989. 
Competitive reactions to market entry: explaining interfirm differences. Journal of Marketing Research 26 (1), 44-55.

Gatignon, H., Robertson, T.S., and Fein, A.J., 1997. Incumbent defense strategies against new product entry. International Journal of Research in Marketing 14 (2), 163-176.

Gupta, S.K., and Krishnan, K.S., 1967. Mathematical models in marketing. Operations Research 15 (6), 10401050 .

Haley, R.J., 1968. Benefit segmentation: A decisionoriented research tool. Journal of Marketing 32, 30-35.

Hauser J.R., 1988. Competitive price and positioning strategies. Marketing Science 7, 76-91.

Hauser, J.R., and Shugan, S.M., 1983. Defensive marketing strategies. Marketing Science 2 (4), 319-360.

Hauser, J.R., 1988. Competitive price and positioning strategies. Marketing Science 7 (1), 76-91.

Henderson, B.D., 1983. The anatomy of competition. Journal of Marketing 47, 7-11.

Hotelling, H., 1929. Stability in competition. Economic Journal, 41-57.

Hunt, S.D., and Duhan, D.F., 2002. Competition in the third millennium: Efficiency or effectiveness? Journal of Business Research 55 (2), 97-102.

Kannan P.K., and Wright, G.P., 1991. On testing competitive market structures. Marketing Science 10, 338-345.

Ketchen D.J.Jr., and Shook, C.L., 1996. The application of cluster analysis in strategic management research: An analysis and critique. Strategic Management Journal 17, 441-458.

Kotler, P., 1965. Competitive strategies for new product marketing over the life cycle. Management Science 12 (4), 104-119.

Kotler, P., 1999. Kotler on Marketing: How to Create, Win, and Dominate Markets, The Free Press, New York.

Kotler, P., 2003. Marketing Management, 11th Ed., Prentice Hall, Upper Saddle River.

Krieger, A.M., and Green, P.E. 1996. Modifying clusterbased segments to enhance agreement with an exogeneous response variable. Journal of Marketing Research 33, 351-363.
Kuester, S., Homburg, C., and Robertson, T.S., 1999. Retaliatory behavior to new product entry. Journal of Marketing 63 (4), 90-106.

Lane, W.J., 1980. Product differentiation in a market with endogenous sequential entry. The Bell Journal of Economics 11 (1), 237-260.

Lilien, G.L., and Rangaswamy, A. 2000. Marketing Engineering: Computer-Assisted Marketing Analysis and Planning, Addison-Wesley, Mass.

Mazanec, J., and Strasser, H., 2000. A Nonparametric Approach to Perceptions-Based Market Segmentation: Foundations, Springer, Berlin.

McAfee, R.P., and McMillan, J., 1996. Competition and game theory. Journal of Marketing Research 33 (3), 263267.

McDonald, M., and Payne, A., 1996. Marketing Planning for Services, Butterworth-Heinemann, Oxford.

McDonald, M., 2002. The Essential Guide to Marketing Planning, Kogan Page, London.

McGuire, T.W., and Staelin, R., 1983. An industry equilibrium analysis of downstream vertical integration. Marketing Science 2 (2), 161-191.

Milligan, G.W., and Cooper, M.C., 1985. An examination of procedures for determining the number of clusters in data sets. Psychometrika 50, 159-179.

Milligan, G.W., 1981. A monte carlo study of thirty internal criterion measures for cluster analysis. Psychometrika 46, 187-199.

Moorthy, K.S., 1985. Using game theory to model competition. Journal of Marketing Research 22, 262282.

Moorthy, K.S., 1988. Product and price competition in a duopoly. Marketing Science 7, 141-168.

Myers, J.H., and Tauber, E.,1977. Market Structure Analysis, American Marketing Association, Chicago.

Novak, T.P., Stangor, C., 1987. Testing competitive market structures: An application of weighted least squares methodology to brand switching data. Marketing Science 6, 82-97.

Oxenfeldt, A.R., Moore, W.L., 1978. Customer or competitor: Which guideline for marketing? Management Review 67 (8), 43-48.

Porter, M., 1980. Competitive Strategy: Techniques For 
Analyzing Industry and Competitors, The Free Press, New York.

Punj, G., and Stewart, D.W., 1983. Cluster analysis in marketing research: Review and suggestions for application. Journal of Marketing Research 20, 134-148.

Putsis, W.P., and Dhar, R., 1998. The many faces of competition. Marketing Letters 9 (3), 269-284.

Ramaswamy, V., Gatignon, H., and Reibstein, D.J., 1994. Competitive marketing behaviour in industrial markets. Journal of Marketing 58 (2), 45-55.

Rao, A.G., and Shakun, M.F., 1972. A quasi-game theory approach to pricing. Management Science 18 (5), 110123.

Rao, R.C., and Bass, F.M., 1985. Competition, strategy, and price dynamics: A theoretical and empirical investigation. Journal of Marketing Research 22 (3), 283-296.

Robinson, W.T., 1988. Marketing mix reactions to entry. Marketing Science 7 (4), 368-385.

Schmalensee, R., 1978. A model of advertising and product quality. Journal of Political Economy 86 (3), 485-503.

Schnaars, S.P., 1998. Marketing Strategy: Customers and Competition, 2nd Ed, The Free Press, New York.

Shakun, M.F., 1965. Advertising expenditures in coupled markets - A game-theory approach. Management Science 11 (4), 42-47.

Slade, M.E., 1995. Product rivalry with multiple strategic weapons: An analysis of price and advertising competition. Journal of Economics and Management Strategy 4 (3), 445-476.

Smith, K.G., Grimm, C.M., Gannon, M.J., Chen, M.J., 1991. Organizational information processing, competitive responses, and performance in the U.S. domestic airline industry. Academy of Management Journal 34 (1), 60-85.

Spence, A.M., 1981. The learning curve and competition. The Bell Journal of Economics 12 (1), 49-70.

Stearns, T.M., Carter, N.M., Reynolds, P.D., Williams, M.L., 1995. New firm survival: Industry, strategy, and location. Journal of Business Venturing 10, 23-42.

Thompson, G.L., Teng, J.T., 1984. Optimal pricing and advertising policies for new product oligopoly models. Marketing Science 3 (2), 148-168.
Thorndike, R.L., 1953. Who belongs in the family? Psychometrika 18, 267-276.

Urban, G.L., Johnson, P.L., and Hauser, J.R., 1984. Testing competitive market structures. Marketing Science 3, 83-112.

Vandenbosch, M.B., and Weinberg, C.B., 1995. Product and price competition in a two-dimensional vertical differentiation model. Marketing Science 14, 224-249.

Wang, Q., and Wu, Z., 2001. A duopolistic model of dynamic competitive advertising. European Journal of Operational Research 128 (1), 213-226.

Wedel, M., and Kamakura, W., 1998. Market Segmentation - Conceptual and Methodological Foundations, Kluwer Academic Publishers, Boston.

Weitz, B.A., 1985. Introduction to special issue on competition in marketing. Journal of Marketing Research 22 (3), 229-236.

Wesson, T., and De Figueiredo, J.N., 2001. The importance of focus to market entrants: A study of microbrewery performance. Journal of Business Venturing 16, 377-403.

Wind, Y., 1978. Issues and advances in segmentation research. Journal of Marketing Research 15 (3), 317337.

\section{Biographies}

Dr Sara Dolnicar is Associate Professor at the School of Management \& Marketing at the University of Wollongong. She completed her Masters degree in Psychology at the University of Vienna and her $\mathrm{PhD}$ degree in business administration at the Vienna University of Economics and Business Administration, where she worked from 1994 to 2002 as Assistant Professor. During this time she acted as Secretary General of the Austrian Society for Applied Research in Tourism located in Vienna, Austria. Her research interests centre on issues of integrated market structure analysis.

Roman Freitag presently works at the Federal Ministry of Social Security, Generations and Consumer Protection in the Social Insurance department. He completed his Masters degree in business administration at the Vienna University of Economics and Business Administration where he worked from 2000 to 2003 as a research assistant at the Department of Mathematical Modelling and Information Systems in Economics and Management Science (a joint endeavor of three universities in Vienna and funded by the Austrian 
Research Foundation). His research interests centre around simulation and queuing systems.

Melanie Randle completed a Masters of Business (Marketing) at Charles Sturt University in 1999 and is presently studying a $\mathrm{PhD}$ at the School of Management \& Marketing at the University of Wollongong. Her PhD study investigates heterogeneity of motivations for volunteering within a highly multicultural community and is funded by an Australian Research Council Linkage grant. Her research interests include social marketing and volunteering.

\section{Correspondence address}

Sara Dolnicar, School of Management \& Marketing, University of Wollongong, Northfields Ave, 2522 Wollongong, NSW Australia. Telephone: +61 (2) 4221 3862, Email: sarad@uow.edu.au; Roman Freitag, Federal Ministry of Social Security, Generations and Consumer Protection, Social Insurance Department, Stubenring 1, A-1010 Wien, Austria, Telephone: +01 71100 6358, Email: romanfreitag@yahoo.com; Melanie Randle, School of Management \& Marketing, University of Wollongong, Northfields Ave, 2522 Wollongong, NSW Australia, Telephone: +61 (2) 4221 5528, Email: mjr46@uow.edu.au 